\title{
UJI PENGIKATAN KOLESTEROL OLEH EKSTRAK METANOL BEKATUL BERAS KETAN HITAM SECARA IN VITRO
}

\author{
Dewi Kurnia*, Nenden Ayu Lisniawati, Deden Indra Dinata \\ Sekolah Tinggi Farmasi Bandung \\ *email: dewi.kurnia@stfb.ac.id
}

Received 11 May 2019

Accepted 28 June 2019

\begin{abstract}
Abstrak
Beras ketan hitam merupakan varietas lokal yang mengandung pigmen paling baik, dibandingkan dengan beras putih atau beras warna lain. Warna hitam pada beras ketan hitam berasal dari lapisan bekatul dan bagian bulir berasnya yang mengandung pigmen antosianin berwarna ungu. Bekatul beras ketan hitam mengandung serat serealia yang baik bagi organ pencernaan. Pada penelitian ini dilakukan pengujian pengikatan kolesterol oleh ekstrak metanol bekatul beras ketan hitam. Ekstraksi dilakukan dengan cara maserasi menggunakan metanol $70 \%$ dalam kondisi asam (penambahan $\mathrm{HCl} 1 \%$ ). Uji pengikatan kolesterol oleh ekstrak metanol bekatul beras ketan hitam dilakukan secara in vitro dengan metode pembentukan kompleks kolesterol dengan $\mathrm{FeCl}_{3}$. Serapan kolesterol bebas diukur menggunakan spektrofotometer sinar tampak pada serapan maksimum panjang gelombang $526 \mathrm{~nm}$. Randemen ekstrak yang diperoleh adalah sebesar 17,53\%. Identifikasi ekstrak menggunakan KLT dengan eluen butanol : asam asetat : air (4,5:1:4,5) menunjukan adanya senyawa golongan antosianin. Hasil uji pengikatan kolesterol menunjukkan bahwa ekstrak metanol bekatul beras ketan hitam dengan konsentrasi 20 ppm dapat menurunkan kolesterol sebesar 47,46\%. Peningkatan konsentrasi ekstrak menunjukan semakin besar pula penurunan kadar kolesterol bebas.
\end{abstract}

Kata kunci: bekatul beras ketan hitam, pengikatan kolesterol, antosianin, in vitro, spetkrofotometer sinar tampak

\begin{abstract}
Black glutinous rice is a local variety that contains the best pigments, as opposed to white rice or other color rice. The black color in black glutinous rice comes from the lining of the bran and the layer of the heat which contain a purple anthocyanin pigment. Black glutinous rice bran contains a good cereal fiber for the digestive organs. In this study, cholesterol binding testing was conducted on the extract of methanol bran in black glutinous rice. Extraction is carried out by maceration using methanol $70 \%$ in acidic conditions $(\mathrm{HCl} 1 \%)$. Test cholesterol binding by the extract of the black glutinous rice bran in vitro by the forming cholesterol complexes with $\mathrm{FeCl}_{3}$ method. Free cholesterol uptake is measured using spectrophotometers visible at maximum absorption of $526 \mathrm{~nm}$ wavelengths. The extract yield obtained was $17.53 \%$. Identification of extracts using TLC with eluent buthanol : acetic acid : water $(4.5: 1: 4,5)$ indicates the presence of anthocyanin compounds. The results of cholesterol binding test showed that the ethanol extract of black glutinous rice bran with a concentration of $20 \mathrm{ppm}$ can lower cholesterol by $47.46 \%$. An increase in the concentration of the extract showed more reduction in free cholesterol levels.
\end{abstract}


Keywords: Black glutinous rice bran, cholesterol binding, in vitro, anthocyanin, spectrophotometer visible

\section{Pendahuluan}

Jumlah penderita penyakit kardiovaskular dari tahun ke tahun mengalami peningkatan yang cukup tinggi. Salah satu faktor penyebabnya adalah pola makanan yang kurang baik, misalnya mengkonsumsi makanan cepat saji, gorengan, merokok, dan minuman beralkohol. Mengkonsumsi makanan yang berlemak dapat meningkatkan kadar kolesterol dalam plasma. Kadar kolesterol tinggi dalam darah dapat membentuk endapan pada dinding pembuluh darah sehingga menyebabkan penyempitan pembuluh darah yang disebut aterosklerosis. Penyempitan pada pembuluh darah jantung menyebabkan penyakit jantung koroner dan bila mengendap pada pembuluh darah di otak menyebabkan penyakit serebrovaskuler (Sudiarti, 2011). Oleh karena itu, menjaga asupan makanan agar tidak menyebabkan kadar kolesterol tinggi dalam plasma sangat penting untuk menurunkan faktor resiko terjadinya penyakit jantung koroner (PJK).

Bekatul adalah bagian terluar dari bagian bulir, termasuk sebagian kecil endosperm berpati. Biasanya pemanfaatan bekatul padi lebih banyak ditujukan sebagai pakan ternak. Bekatul beras ketan hitam merupakan fiber yang kaya akan serat dan sering dihilangkan pada saat penggilingan beras. Bekatul ini telah diteliti mengandung senyawa bioaktif diantaranya tokoferol, tokotrienol, oryzanols, vitamin B kompleks, dan senyawa fenolik. Kandungan yang penting adalah antosianin yaitu suatu suatu pigmen alami yang termasuk dalam keluarga besar flavonoid yang larut dalam air, yang bertanggung jawab memberikan warna merah, ungu, dan biru pada tanaman (Zhang et al., 2010). Pada penelitian yang dilakukan oleh Fajrin (2010), diketahui bahwa ekstrak etanol beras ketan hitam mengandung senyawa antioksidan jenis antosianin yang dapat menghambat oksidasi Low Density Lipoprotein (LDL) pada tikus putih jantan yang diberi perlakuan minyak goreng bekas pakai. Karena LDL yang teroksidasi dapat menyebabkan viskositas darah menjadi lebih kental dan menyebabkan resiko terjadinya penyumbatan pembuluh darah (asterosklerosis) menjadi lebih tinggi.

Dari ketiga jenis beras yaitu beras putih, beras merah dan bersa hitam, diketahui kadar antosianin tertinggi terdapat pada ekstrak bekatul beras (Widarta, Nocianitri and Sari, 2013). Ekstrak bekatul beras hitam memiliki kandungan total fenolik yang tinggi dan aktivitas sebagai peredam radikal bebas seperti beras merah. Sedangkan ekstrak bekatul beras putih menunjukkan kandungan fenolik dan aktivitas antioksidan terendah.

Bekatul beras mengandung serat serealia, yakni serat pangan yang kualitasnya paling baik bagi organ pencernaan. Selain itu, dalam bekatul tersebut juga terkandung minyak nabati yang kaya akan asam amino, vitamin B dan mineral. Kandungan bekatul juga memberikan efek kenyang dan membersihkan saluran pencernaan. Manfaat lainnya juga dapat menurunkan kadar gula dan kolesterol darah, sehingga sangat bermanfaat untuk mencegah penyakit diabetes dan penyakit lain yang berhubungan dengan kolesterol seperti aterosklerosis dan PJK (Sarasvati, 2008).

\section{Metode Penelitian}

\section{Alat dan Bahan}

Alat yang digunakan adalah neraca analitik, gelas piala, gelas ukur, labu ukur, corong, kaca arloji, cawan penguap, kertas saring, evaporator, pipet tetes, pipet 
volum dan bulp, batang pengaduk, spatula, camber, tabung reaksi, vortex, termometer, penangas air, evaporator, sentrifuga, mikropipet, kuvet, spektrofotometer UV-Vis. Sedangkan bahan-bahan yang digunakan adalah ketan hitam, metanol 70\%, metanol p.a, $\mathrm{HCl}$ pekat, $\mathrm{CH}_{3} \mathrm{COOH}$, butanol, $\mathrm{NaOH}$, plat KLT $\mathrm{GF}_{254}$, aquadest, kolesterol murni, $\mathrm{FeCl}_{3}$, isopropanol.

\section{Prosedur Penelitian}

Sampel bekatul beras ketan hitam diambil dari penggilingan padi di Desa Sukajaya, Sumedang Selatan. Sampel yang didapat diayak dan disimpan di dalam wadah tertutup dan tempat gelap. Sebanyak 300 gram sampel diekstraksi dengan teknik maserasi menggunakan $1000 \mathrm{ml}$ larutan metanol $70 \%$ dalam suasana asam (penambahan $\mathrm{HCl} 1 \%$ ). Proses maserasi dilakukan dalam wadah botol kaca berwarna gelap selama $3 \times 24$ jam dengan penggantian pelarut setiap 24 jam. Kemudian ekstrak disaring menggunakan kertas saring dan filtrat yang diperoleh kemudian dipekatkan dengan evaporator (Suhartatik, 2013).

\section{Analisis Kualitatif Antosianin}

\section{Uji Warna}

Ke dalam tabung reaksi, sebanyak 1 $\mathrm{mL}$ ekstrak bekatul beras ketan hitam ditambahkan $1 \mathrm{~mL} \mathrm{HCl} 2 \mathrm{M}$ kemudian dipanaskan sampai mendidih selama 5 menit. Ekstrak dinyatakan positif mengandung antosianin jika berubah menjadi warna merah. Selanjutnya bila ditambahkan $\mathrm{NaOH} 2 \mathrm{M}$ tetes per tetes warna merah tersebut akan berubah menjadi warna hijau biru dan memudar secara perlahan (Harborne, 1998).

\section{Uji Kromatografi Lapis Tipis (KLT)}

Fase diam yang digunakan adalah silica gel GF254 dengan fase gerak butanol:asam asetat:aquades $(4,5: 1: 4,5)$. Pita hasil pemisahan diamati di bawah lampu sinar UV dan nilai Rf dari pita yang dihasilkan dibandingkan dengan tabel referensi antosianin (Harborne, 1998).

\section{Pembuatan Larutan}

Larutan induk kolesterol 1000 ppm dibuat dengan menimbang $100 \mathrm{mg}$ kolesterol dilarutkan dengan isopropanol dalam labu ukur $100 \mathrm{ml}$. Larutan $\mathrm{FeCl}_{3}$ dibuat dengan cara melarutkan sebanyak 8,4 gram $\mathrm{FeCl}_{3}$ dalam $100 \mathrm{~mL}$ asam asetat 1\%. Pereaksi ini disimpan dalam botol gelap. Pembuatan larutan induk ekstrak bekatul 1000 ppm dilakukan dengan melarutkan $10 \mathrm{mg}$ ekstrak bekatul ketan hitam dalam labu ukur $100 \mathrm{ml}$, selanjutnya dilarutkan dengan metanol sampai tanda batas.

\section{Pembuatan Kurva Standar Kolesterol}

Dari larutan induk kolesterol 1000 ppm dibuat seri pengenceran dengan konsentrasi $80 ; 100 ; 120 ; 140 ; 160$; dan 180 ppm. Selanjutnya pada setiap konsentrasi diambil sebanyak $2,5 \mathrm{ml}$ ke dalam tabung reaksi. Masing-masing konsentrasi ditambahkan $2 \mathrm{ml}$ pereaksi $\mathrm{FeCl}_{3}$. Kemudian di vortex dan dibiarkan selama 30 menit pada suhu kamar. Larutan dibaca absorbansinya menggunakan spektrofotometer sinar tampak pada panjang gelombang $526 \mathrm{~nm}$. Kurva standar in digunakan untuk menentukan konsentrasi kolesterol yang tersisa.

\section{Pembuatan Larutan Uji Ekstrak Bekatul Beras ketan Hitam}

Dari larutan induk ekstrak bekatul beras ketan hitam 1000 ppm diambil sebanyak $100 \mu \mathrm{l}, 120 \mu \mathrm{l} ; 140 \mu \mathrm{l} ; 160 \mu \mathrm{l}$; $180 \mu \mathrm{l}$; dan $200 \mu \mathrm{l}$, dimasukkan kedalam labu ukur $10 \mathrm{ml}$, selanjutnya dilarutkan dengan metanol sampai tanda batas. Konsentrasi larutan yang dihasilkan adalah 10; 12; 14; 16; 18; dan 20 ppm. 


\section{Pengukuran Kadar Kolesterol Bebas}

Sebanyak $5 \mathrm{~mL}$ dari masing-masing konsentrasi larutan uji ekstrak diambil kemudian masing-masing ditambahkan 5 ml larutan kolesterol 180 ppm. Campuran larutan dihomogenkan dan diinkubasi selama 60 menit pada suhu $37^{\circ} \mathrm{C}$, kemudian disentrifuga selama 5 menit dengan kecepatan 4000rpm. Sebanyak 5 $\mathrm{mL}$ supernatan yang dihasilkan diambil kemudian ditambahkan dengan $2 \mathrm{ml}$ pereaksi $\mathrm{FeCl}_{3}, \quad$ selanjutnya dihomogenkan dan didiamkan selama 30 menit pada suhu kamar. Pengukuran serapan larutan dilakukan menggunakan spektrofotometer sinar tampak dengan panjang gelombang $526 \mathrm{~nm}$ (Puspitasari, 2014). Kurva standar digunakan untuk menentukan konsentrasi kolesterol yang tersisa. persentasi penurunan kolesterol dihitung menggunakan persamaan sebagai berikut :

$$
A=\frac{C-B}{B} \times 100 \%
$$

Dimana :

$\mathrm{A}=$ persentase penurunan kolesterol

$\mathrm{B}=$ konsentrasi kolesterol akhir

$\mathrm{C}=$ konsentrasi kolesterol awal

\section{Hasil dan Pembahasan}

Teknik ekstraksi yang dilakukan pada penelitian ini adalah metode maserasi. Maserasi merupakan proses perendaman sampel dengan pelarut organik yang digunakan pada suhu ruangan. Hal ini dilakukan untuk memperoleh senyawa antosianin yang bersifat termolabil. Metode maserasi ini adalah metode yang sangat menguntungkan untuk senyawa yang termolabil. Pada proses ekstraksi juga dilakukan penambahan $\mathrm{HCl}$ hal ini dimaksudkan untuk menstabilkan senyawa antosianin yang terkandung dalam kulit ari ketan hitam. Stabilitas antosianin dipengaruhi oleh $\mathrm{pH}$, oksigen, suhu dan cahaya (Samber dkk, 2011).

Antosianin memiliki cincin aromatik yang mengandung gugus polar (hidroksi, karboksi, metoksi) dan residu glikosil yang menghasilkan molekul polar dengan keadaannya yang polar, antosianin lebih mudah larut dalam pelarut polar seperti metanol sedangkan asam klorida dalam pelarut akan mendenaturasi membran sel kemudian melarutkan pigmen antosianin keluar dari sel. Dari hasil pemekatan filtrat diperoleh ekstrak sebanyak 52,59 gram atau setara dengan randemen $17,53 \%$ terhadap berat sampel.

Ekstrak pekat selanjutnya dianalisis secara kualitatif dengan pengujian warna. Pengujian warna dilakukan dengan penambahan $\mathrm{HCl}$ dan $\mathrm{NaOH}$. Dari hasil pengujian warna diketahui senyawa yang terkandung pada kulit ari ketan hitam adalah senyawa antosianin. Hal ini ditunjukan pada saat penambahan $\mathrm{HCl}$ $2 \mathrm{M}$ yang kemudian dipanaskan terjadi perubahan warna dari warna hitam (warna ekstrak) menjadi warna merah. Sampel yang telah dipanaskan tersebut ditambahkan $\mathrm{NaOH} 2 \mathrm{M}$, kemudian terjadi perubahan warna dari merah menjadi hijau kebiruan, namun warna tersebut perlahan-lahan memudar.

a.

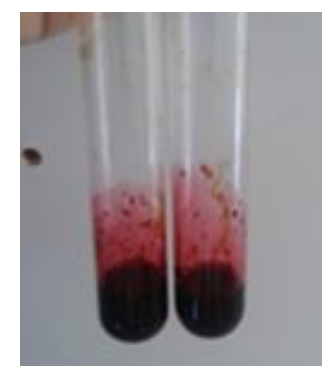

b.

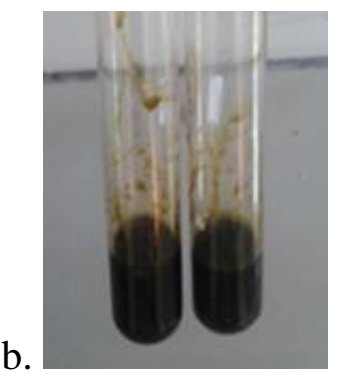

Gambar 1. Uji warna antosianin; a) penambahan $\mathrm{HCl} 2 \mathrm{M}$; b) Penambahan $\mathrm{NaOH}$ $2 \mathrm{M}$

Perubahan warna pada gambar 1 disebabkan oleh adanya perubahan struktur pada antosianin akibat pengaruh ion $\mathrm{H}^{+}$dan ion $\mathrm{OH}^{-}$. Dibawah ini merupakan perubahan struktur yang terjadi: 
<smiles>Oc1cc(O)c2cc(-c3ccc(O)c(O)c3)c(O)cc2c1</smiles>

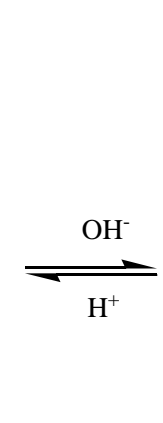<smiles>OC1=C(O)C(O)(c2ccc(O)c(O)c2)c2c(O)cc(O)cc2OC1</smiles>

Gambar 2. (a) antosianin dalam kondisi asam dan (b) antosianin dalam kondisi basa (Hayati, dkk. 2012)

Salah satu kestabilan senyawa antosianin yaitu dipengaruhi oleh $\mathrm{pH}$. Senyawa antosianin lebih stabil dalam suasana asam dibandingkan dengan suasana basa.

Identifikasi selanjutnya menggunakan kromatografi lapis tipis untuk membuktikan senyawa yang terkandung pada sampel bekatul beras ketan hitam adalah senyawa antosianin. Fase diam yang digunakan yaitu silika gel $\mathrm{GF}_{254}$ dengan fase gerak BAA (butanol:asam asetat:aquadest $=4,5: 1: 4,5)$. Penggunaan fase gerak BAA dikarenakan fase gerak tersebut memberikan $\mathrm{hRf}$ sedang yaitu berkisar antara 68-71. Polaritas fase gerak akan menentukan kecepatan migrasi zat terlarut yang selanjutnya akan menentukan nilai Rf. Fase gerak yang memiliki polaritas yang rendah akan meminimalkan serapan komponen terhadap campuran pelarut sehingga hingga $\mathrm{Rf}$ akan meningkat secara signifikan. Hasil identifikasi antosianin dari ekstrak kulit ari ketan hitam dibandingkan dengan hasil sesuai literatur Harborne (1998). Plat KLT hasil pemisahan kemudian diamati dibawah sinar UV $366 \mathrm{~nm}$. Terdapat noda berwarna magenta dengan hRf 70 yang menunjukan bahwa pita tersebut adalah senyawa antosianin (Gambar 3).

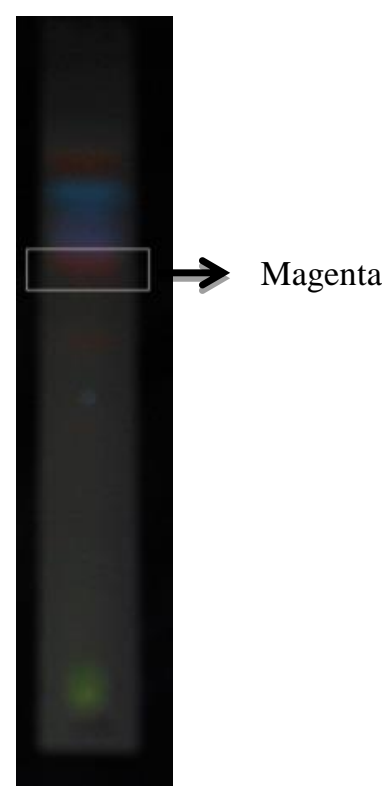

Gambar 3. Hasil identifikasi dengan KLT dibawah sinar UV $366 \mathrm{~nm}$

Untuk keperluan uji pengikatan kolesterol secara in vitro, dibuat kurva larutan deret standar kolesterol yang untuk mendapatkan persamaaan regres linier. Analisis dilakukan menggunakan spektrofotometer sinar tampak pada panjang gelombang 526. Berikut adalah data serapan deret dan kurva kalibrasi untuk standar kolesterol. 
Tabel 1. Data serapan standar kolesterol

\begin{tabular}{cc}
\hline Konsentrasi (ppm) & Serapan \\
\hline 80 & 0,377 \\
100 & 0,390 \\
120 & 0,412 \\
140 & 0,423 \\
160 & 0,437 \\
180 & 0,450 \\
\hline
\end{tabular}

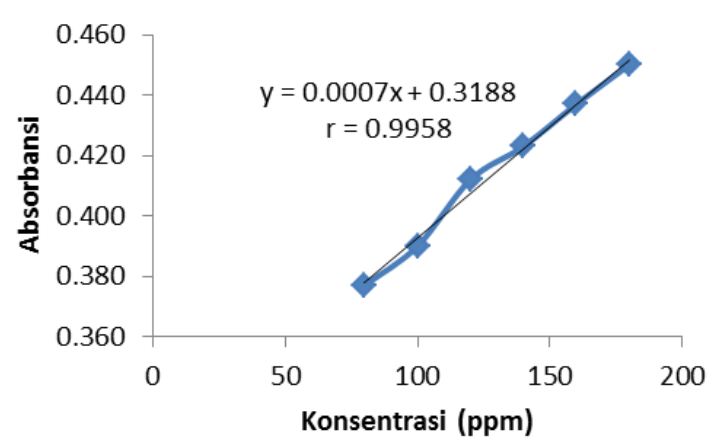

Gambar 4. Kurva kalibrasi standar kolesterol

Berdasarkan hasil pengukuran serapan deret standar kolesterol diperoleh persamaan linear $\mathrm{y}=0,0007 \mathrm{x}+0,3188$ dengan nilai $r=0,9958$. Persamaan ini digunakan pada perhitungan kolesterol bebas yang tidak terikat oleh sampel ekstrak bekatul beras ketan hitam.

Pengujian pengikatan kolesterol dilakukan secara in vitro oleh sampel ekstrak bekatul ketan hitam pada berbagai konsentrasi. Hal ini bertujuan untuk melihat pengaruh konsentrasi ekstrak kulit ari bekatul ketan hitam terhadap kemampuannya untuk mengikat kolesterol. Sampel dengan konsentrasi 10 , $12,14,16,18$, dan 20 ppm ditambahkan dengan larutan kolesterol $180 \mathrm{ppm}$. Supernatan yang dihasilkan pada proses sentrifuga selanjutnya ditambahkan dengan pereaksi $\mathrm{FeCl}_{3}$ untuk membentuk senyawa komplek berwarna. Intansitas warna yang dihasilkan terjadi karena reaksi antara kolesterol bebas dengan $\mathrm{FeCl}_{3}$. Warna yang terbentuk kemudian diukur pada panjang gelombang $526 \mathrm{~nm}$.
Berikut asalah data serapan kolesterol bebas setelah penambahan ekstrak bekatul ketan hitam.

Tabel 2. Kadar Kolesterol bebas setelah direaksikan dengan ekstrak bekatul

\begin{tabular}{ccc}
\hline $\begin{array}{c}\text { Kons ekstrak } \\
(\mathrm{ppm})\end{array}$ & $\begin{array}{c}\text { Kadar } \\
\text { kolesterol bebas } \\
(\mathrm{ppm})\end{array}$ & $\begin{array}{c}\text { \% Penurunan } \\
\text { Kolesterol }\end{array}$ \\
\hline 10 & 178,75 & 0,69 \\
12 & 166 & 7,78 \\
14 & 138,85 & 22,86 \\
16 & 121,74 & 32,38 \\
18 & 113,14 & 37,14 \\
20 & 94,57 & 47,46 \\
\hline
\end{tabular}

Data pada Tabel 2 menunjukkan bahwa pada konsentrasi tertinggi 20 ppm ekstrak kulit ari ketan hitam mempunyai kemampuan tertinggi sebagai penurun kolesterol yaitu sebesar 47,46\%. Penurunan kolesterol bebas terjadi seiring dengan semakin meningkat dengan meningkatnya konsentrasi ekstrak yang ditambahkan. Ekstrak bekatul beras ketan hitam dapat menurunkan konsentrasi kolesterol karena adanya senyawa antosianin, mekanisme kerjanya yaitu dengan menghambat proses aterogenesis dengan mengoksidasi lemak jahat dalam tubuh, sehingga kolesterol yang terdiri dari lemak jahat dapat segera larut. Kandungan senyawa antosianin juga diketahui dapat melindungi integritas sel endotel yang melapisi dinding pembuluh darah sehingga tidak terjadi kerusakan (Fajrin, 2010).

\section{Kesimpulan}

Ekstrak bekatul ketan hitam berpotensi menurunkan kolesterol secara in vitro. Hal ini ditunjukan oleh pengikatan kolesterol tertinggi pada konsentrasi ekstrak 20 ppm yaitu penurunan kolesterol bebas sebesar 47,46 \%. Semakin besar konsentrasi ekstrak 
bekatul, maka semakin banyak kolesterol yang dapat diikat sehingga kolesterol

\section{Daftar Pustaka}

Fajrin, F. A. (2010) : Aktivitas Ekstrak Etanol Ketan Hitam Untuk Menurunkan Kadar Kolesterol, Jurnal Farmasi Indonesia, 5, 63 69.

Harborne, J. B. (1998) : Phytochemical Methods A Guide to Modern Techniques of Plant Analysis, Springer Science \& Business Media, London, 67.

Hayati, E.K., Budi, U.S., dan Hermawan, R. (2012) : Konsentrasi Total Senyawa Antosianin Ekstrak kelopak Bunga Rosella (Hibiscus sabdariffa L.) Pengaruh Temperatur dan $\mathrm{pH}$, Jurnal Kimia, 2, 138 - 147.

Puspitasari, Melia. (2014). Efek Iridiasi Gamma Terhadap Kemampuan Kitosan Dalam Menurunkan Kadar Kolesterol Secara In Vitro, Skripsi sarjana Farmasi, UIN Syarif Hidayatullah, Jakarta.

Samber dkk. (2011) : Karakteristik Antosianin Sebagai Pewarna Alami. Seminar Nasional Pendidikan Biologi FKIP UNS.

Sarasvati Tim. (2008) : Rainbow Diet, PT. Gramedia Pustaka Utama, Jakarta.

Sudiarti, T dan Indrawani, Y.M. (2011) : Gizi dan Kesehatan Masyarakat Edisi 1, Rajawali Pers, Jakarta.

Suhartatik, N., Cahyanto, M.N., Raharjo, S., dan Rahayu, E.S. (2013) : Aktivitas Antioksidan Antosianin Beras Ketan Hitam Selama Fermentasi, Jurnal Teknologi dan Industri Pangan, 24, 115 - 119.

Widarta, I.W.R., Nocianitri, K.A., dan Sari, L.P.I.P., (2013) : Ekstraksi Komponen Bioaktif Bekatul Beras bebas semakin sedikit.

Lokal Dengan Beberapa Jenis Pelarut, Jurnal Aplikasi Teknologi Pangan, 2, 75 - 79.

Zhang, M. W. et al. (2010) 'Phenolic profiles and antioxidant activity of black rice bran of different commercially available varieties', Journal of Agricultural and Food Chemistry, 58(13), pp. 7580-7587. doi: 10.1021/jf1007665. 